\title{
Biomass burning and its effects on health
}

The recent article by Arbex and colleagues, provides a useful and important review of the health effects of biomass burning ${ }^{(1)}$. There is ample evidence that breathing combustionrelated fine particulate matter has adverse health effects. Epidemiologic evidence suggests that short-term exposure exacerbates existing cardiovascular and pulmonary disease and increases the risk of becoming symptomatic, requiring medical attention, or even dying. Long-term repeated exposure appears to increase the risk of chronic pulmonary and cardiovascular disease. Recent studies have attempted to evaluate potential mechanistic pathways that link exposure to fine particulate matter and cardiopulmonary morbidity and mortality. General mechanistic pathways likely include pulmonary and systemic inflammation, enhanced initiation and progression of atherosclerosis, and altered cardiac autonomic function ${ }^{(2)}$.

Particulate air pollution is a mixture of particles that vary in size, composition, and origin. Coarse particles (often defined as particles with an aerodynamic diameter greater than 2.5 micrometers) are derived primarily from soil or other crustal and natural materials. Fine particles (particles less than 2.5 micrometers) are derived chiefly from combustion or are secondary particles such as sulfate and nitrate particles generated by conversion from primary sulfur and nitrogen oxide combustion-related emissions. With regards to the size and source of particles, an overall review of the literature provides two important general observations: 1) Observed cardiopulmonary health effects are generally more strongly associated with fine combustion-related particles than with the coarse particles. 2) Health effects have been observed from fine particles from a wide variety of combustion sources.

Particles from combustion of various fossil fuels such as coal, diesel, gasoline, and high temperature processes such as smelters and steel mills contribute to regional and urban air pollution that has been consistently associated with adverse cardiopulmonary health effects. As Arbex et al. review and discuss, similar adverse health effects are also associated with particles from combustion of biomass including wood, other vegetation, animal wastes, sugar cane, etc. Much biomass burning occurs indoors for heating and cooking, often without adequate ventilation, resulting in exposure to very high concentrations. Arbex et al. correctly point out that on a world-wide bases, health effects from biomass burning can be extremely large and should not be ignored or forgotten.

Another important and well-studied source of fine particles from plant materials or biomass is tobacco smoke. Cardiopulmonary health effects from environmental exposure to particles from tobacco combustion are well documented ${ }^{(3)}$. Evidence of similar adverse health effects from particles from a wide variety of combustion sources suggest that fine combustion-related particles, regardless of the specific source, invoke similar pathophysiological mechanisms.

This timely paper by Arbex et al. clearly reminds us that, in addition to tobacco smoke and fossil fuel combustion-related air pollution, both indoor and outdoor exposure to air pollutants from biomass burning is an extremely important preventable risk factor for cardiopulmonary disease world wide.

$$
\begin{gathered}
\text { C. Arden Pope 111, PhD } \\
\text { Brigham Young University Provo, } \\
\text { Utah } 84602 \text { - USA } \\
142 \text { FOB }
\end{gathered}
$$

\section{REFERENCES}

1. Arbex MA, Cancedo JED, Pereira LAA, Braga ALF, Saldiva PHN. Biomass burning and health effects, J Bras Pneumol, 2004; 30: 158-75

2. Pope CA 111, Burnett RT, Thurston GD, Thun MJ, Calle EE, Krewski D, Godleski JJ. Cardiovascular mortality and long-term exposure to particulate air pollution: epidemiological evidence of general pathophysiological pathways of disease. Circulation 2004;109:71-7.

3. Jaakkola MS, Samet JM. Summary: workshop on health risks attributable to ETS exposure in the workplace. Environmental Health Perspectives 1999;107:823-7.

\section{EDITOR'S NOTE:}

Additional photographs related to the article "Biomass Burning and its Effects on Health" can be viewed at www.jornaldepneumologia.com.br or at www.scielo.br/jbpneu 